\title{
VALIDATING THE SLIDING MECHANICS OF OFFICE- TYPE FURNITURE USING SHAKE-TABLE EXPERIMENTS
}

\author{
Trevor Z. Yeow ${ }^{1}$, Gregory A. MacRae ${ }^{2}$, Rajesh P. Dhakal ${ }^{3}$ and \\ Brendon A. Bradley ${ }^{4}$
}

(Submitted November 2016; Reviewed June 2017; Accepted July 2017)

\begin{abstract}
Pull-tests and shake-table tests of office-type furniture on carpet and vinyl flooring were performed to obtain friction coefficients, and validate the mechanics of content sliding and current modelling approaches. The static friction coefficient, $\mu_{s}$, for furniture with and without wheels was between $0.13-0.30$ and $0.36-0.45$ on carpet flooring, respectively, and 0.07-0.13 and 0.39-0.45 on vinyl flooring, respectively. The kinetic friction coefficient, $\mu_{k}$, was similar to $\mu_{s}$ for carpet flooring, but was up to $38 \%$ lower for vinyl flooring. Shake-table tests using sinusoidal floor excitations showed that: (i) the sliding force hysteresis loop was elasto-plastic on average, and (ii) peak total floor velocity significantly affected the extent of sliding. While it was found that the maximum sliding displacement obtained by numerical integration methods differed by a factor between 0.3 and 3.0 on a case-by-case basis, the average error was just 5\%. Preliminary sliding analyses of furniture resting on single-degree-of-freedom structures of varying stiffness using a suite of ground motion records were performed. It was found that (i) the extent of sliding was not necessarily more severe in stiffer buildings despite the greater peak total floor acceleration demands, and (ii) considering only $\mu_{k}$ in content sliding analyses still produced reasonably accurate predictions.
\end{abstract}

\section{INTRODUCTION}

Building contents, such as hospital equipment or furniture, have the potential to slide over large distances as observed from past seismic events [1] and experimental shake-table studies [2,3]; potentially resulting in injuries, damage, and business/operational disruptions [2,4]. Due to this, there is a need to consider content movement in seismic risk assessments $[5,6]$.

Many content sliding studies are numerical in order to feasibly consider the wide range factors that affect content sliding. Examples of such studies includes: (i) development of equations to predict the contents' maximum sliding displacement [7-9], (ii) investigating the influence of building response on the content sliding behaviour [10-12], and (iii) computing a content sliding spectrum [13]

Numerical approaches follows Amonton's and Coulomb's dry friction laws [14], which state that (i) friction force is independent of the contact area, (ii) friction force is proportional to the normal force, and (iii) kinetic friction is independent of sliding velocity. Based on this, the contents' total acceleration with time, $a_{C T}(t)$, can be defined using Equation 1 [15]:

$$
\begin{aligned}
a_{C T}(t)= & a_{F T}(t) \quad \text { when }\left|v_{C R F}(t)\right|=0 \text { and }\left|a_{F T}(t)\right|<\mu_{s} g \text { (1a) } \\
a_{C T}(t)= & -\operatorname{sign}\left(v_{C R F}(t)\right) \mu_{k} g \quad \text { otherwise } \\
\text { where } \quad & a_{F T}(t)=\text { total floor acceleration response history; } \\
& v_{C R F}(t)=\text { relative velocity between content and floor; } \\
& \mu_{s}=\text { static friction coefficient; } \\
& \mu_{k}=\text { kinetic friction coefficient; and } \\
& g=\text { acceleration due to gravity. }
\end{aligned}
$$

Despite the extensive use of Equations $1 \mathrm{a}$ and $1 \mathrm{~b}$ in past studies, there exist few experimental studies which validated this for furniture subjected to seismic shaking. Those which did generally performed shake-table tests of rigid rectangular blocks, which may not be representative of typical office-type furniture, on uncommon flooring materials (e.g. Teflon) $[3,16]$. Typical values of $\mu_{s}$ and $\mu_{k}$ for office environments are thus not well-known.

It had also been observed in past experiment studies, both seismic and non-seismic related [17-20], that: (i) $\mu_{k}$ generally decreased with the content's velocity relative to the floor, $v_{C R F}$, at low $v_{C R F}$ for most materials, and (ii) $\mu_{k}$ may increase with $v_{C R F}$ at higher $v_{C R F}$ values and may even exceed $\mu_{s}$. The latter observation was attributed to the release of thermal energy during sliding, which was dependent on $v_{C R F}$ [20]. The $v_{C R F}$ which triggered the change in $\mu_{k}-v_{C R F}$ trend was dependent on the contact surfaces' materials. Based on these findings, Amonton's and Coulomb's dry friction laws may not be realistic. However, there is mixed opinion on the significance of this in seismic conditions $[16,19,21]$; though these studies have found that $\mu_{k}$ is generally lower than $\mu_{s}$.

In addition to the potential issues regarding the applicability of Amonton's and Coulomb's dry friction laws, there also exists divided opinion on the importance of peak total floor acceleration, $A_{F T}$, on the extent of content sliding. Many studies assumed that the maximum sliding displacement of contents is solely dependent on $A_{F T}[9,22-25]$. However, others had shown that shaking frequency was also important [10-12]; though no experimental studies have demonstrated this for pure sliding cases.

Based on these issues, there is a need for Equations $1 \mathrm{a}$ and $1 \mathrm{~b}$ to be validated for seismic conditions so that content sliding analysis could be confidently used for seismic risk assessments. This study seeks to address these needs, and to better understand the mechanics of furniture sliding in office environments by performing: (i) static and kinetic friction tests;

\footnotetext{
1 Corresponding Author, Postdoctoral Researcher, Department of Civil and Natural Resources Engineering, University of Canterbury, Christchurch, trevor.yeow@canterbury.ac.nz, (Young Professional member)

2 Associate Professor, Department of Civil and Natural Resources Engineering, University of Canterbury, Christchurch(Member)

3 Professor, Department of Civil and Natural Resources Engineering, University of Canterbury, Christchurch (Fellow)

4 Professor, Department of Civil and Natural Resources Engineering, University of Canterbury, Christchurch (Member)
} 
and (ii) shake-table tests using sinusoidal floor motion. Case studies were also examined to demonstrate the usefulness of numerical approaches. For the contents and flooring materials considered, answers to the following questions are sought:

1. What are typical values of $\mu_{s}$ ?

2. What is the ratio between $\mu_{k}$ and $\mu_{s}$ ?

3. How accurate are numerical approaches in predicting the actual content's sliding response?

4. Is peak floor acceleration alone a good descriptor of the sliding response of contents subjected to sinusoidal floor motion? If not, which other parameters are important?

5. How important is the consideration of $\mu_{s}$ and $\mu_{k}$ in numerical approaches?

\section{EXPERIMENTAL DETAILS}

\section{Furniture Properties}

Several office-type furniture items, herein termed 'contents' as to not confuse subscript notation with the floor response, were used in the experiments. These are shown in Figure 1, and consisted of: (i) a desk with rubber soles (D1); (ii) a desk with a metallic base surface without rubber soles (D2); (iii) a mobile drawer unit (MD); and (iv) a white plastic container (WC). These have masses of 24.5, 26.8, 31.3, and $2.2 \mathrm{~kg}$, respectively. Both the drawer and the container are supported on wheels. The drawer's wheels were able to also rotate $360^{\circ}$ in the horizontal plane, while the container's wheels were fixed to only rotate in its longitudinal direction. The drawer's wheels were all realigned to roll in the direction of excitation before each test.

\section{Static and Kinetic Friction Tests Setup}

Three types of tests were performed for each content and floor material pairing: (i) static pull-tests, (ii) kinetic pull-tests, and (iii) dynamic floor shaking. All tests were performed on the shake-table shown in Figure 2a. The shake-table has dimensions of $3.5 \mathrm{~m}$ by $2 \mathrm{~m}$, and was displacement-controlled. Plywood was bolted onto the shake-table to protect the surface, and to allow the flooring materials (carpet and vinyl) to be glued on directly. While this method of installation may not be representative of practice where an underlay material may be used, gluing the flooring material directly to the plywood would prevent it from loosening from repeated tests. This is important to ensure consistency in flooring conditions between each test.

Static pull-tests were used to determine $\mu_{s}$ using the setup shown Figure $2 \mathrm{~b}$, where $\mu_{s}$ was the ratio between the total applied force which initiated sliding, and the content's weight. This was performed five times in each direction to minimize directionality effects and to obtain an average of $\mu_{s}$. The applied load height was initially varied, but was found to have no effect.

The kinetic friction coefficient, $\mu_{k}$, was determined by connecting the content to a reaction frame using a steel rod as shown in Figure 2c. The shake-table was then displaced at rates of 3.0, 7.0 and $10.0 \mathrm{~mm} / \mathrm{s}$ up to $100 \mathrm{~mm}$ from its initial position in each direction. A load cell, connected between the steel rod and the reaction frame, recorded the force required to keep the content stationary. The ratio of this force to the content's weight gives $\mu_{k}$. This test could not be performed for the white container as its sloped sides made it difficult to connect the steel rod without causing uplifting effects. The test was performed twice for other contents; each starting in different directions. For both friction tests, additional weights were placed to observe if $\mu_{s}$ and $\mu_{k}$ had any dependencies on mass.

It should be noted that each of these tests were performed within 10 minutes of each other. It is possible that a longer settling down period could have resulted in different friction coefficients. There were not enough resources to investigate this effect in this study, and so this could be the basis of a future study.

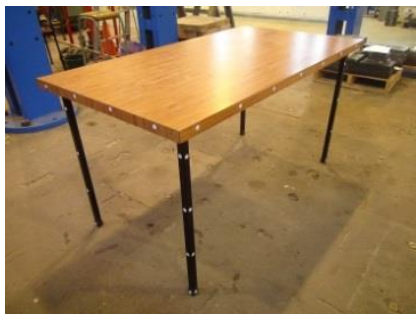

(a)

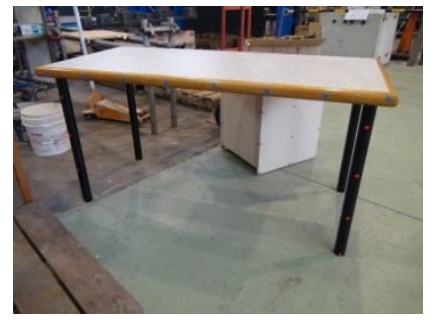

(b)

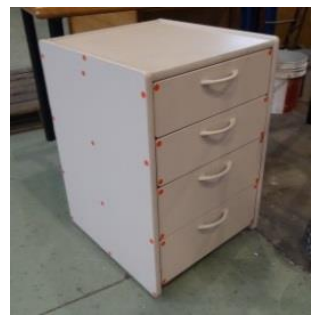

(c)

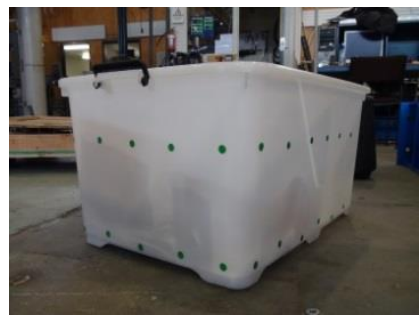

(d)

Figure 1: Contents used in experiments; (a) Desk 1 (rubber soles), (b) Desk 2 (metallic base), (c) Drawer, (d) Container.

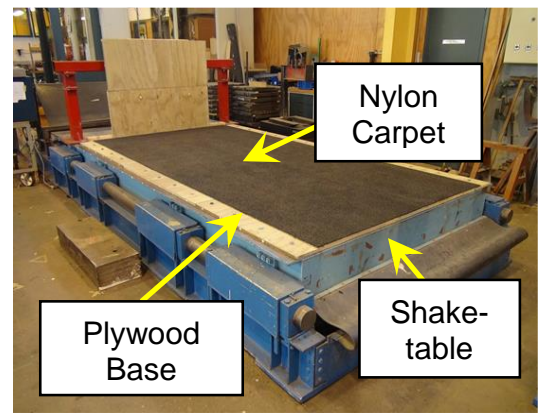

(a)

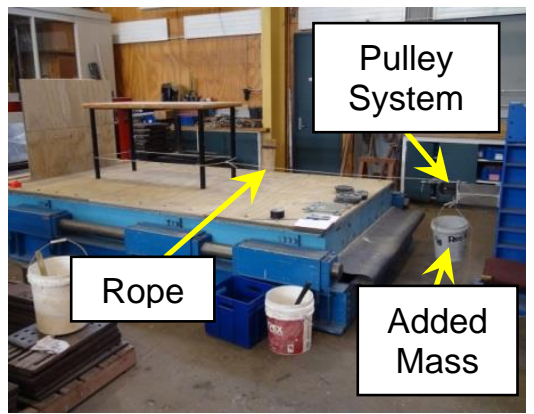

(b)

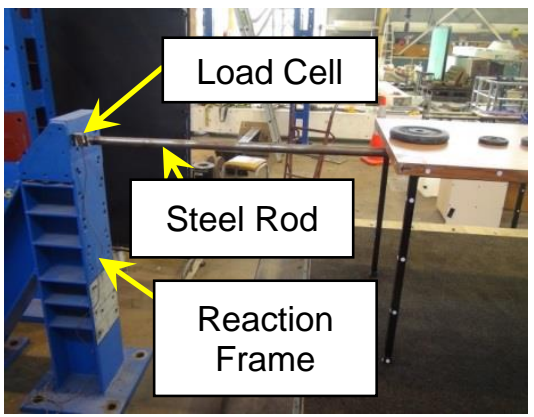

(c)

Figure 2: Testing configuration; (a) Shake table layout, (b) Static friction test, (c) Kinetic friction test. 
Furthermore, due to the presence of wheels for the drawer and container, their response would be a function of its rolling resistance rather than the friction between the content and the flooring surface. However, the rolling resistance itself is a function of friction between the wheels, the wheel axles, and the content. As such, the friction coefficients recorded from these tests are not necessarily the traditional friction coefficients between the content and flooring surface, but one that is more characteristic of their actual response. This may also cover other restraining factors, such as contents digging into the flooring material.

\section{Shake-Table Test Input Motion and Measurements}

Dynamic floor shaking tests was performed considering sinusoidal floor excitations to better understand content sliding mechanics. As shown in Figure 3a, the excitation frequency was kept constant, while its amplitude was (i) increased linearly from zero over the first two seconds, (ii) kept constant for a number of cycles, and (iii) reduced to zero over the final two seconds.

The six amplitude and frequency pairings considered are listed in Table 1. Cases 1, 3, 5, and 6 were selected to give the largest possible shaking inputs without exceeding the shake table's acceleration, velocity, and/or displacement limitation. While a higher frequency but lower amplitude input is possible, the response of the content is much smaller and as such was not considered. Case 2 was added so that comparisons with Case 3 will show the effect of amplitude, while comparisons with Case 5 will show the effect of frequency. Case 4 was selected to enable similar comparisons with Cases 5 and 6 . All content was subjected to each amplitude and frequency pairing twice, with each test starting in a different direction to minimize directionality effects.

Table 1: Sinusoidal floor excitation patterns.

\begin{tabular}{ccccccc} 
& \multicolumn{7}{c}{ Case } \\
\cline { 2 - 7 } Property & $\mathbf{1}$ & $\mathbf{2}$ & $\mathbf{3}$ & $\mathbf{4}$ & $\mathbf{5}$ & $\mathbf{6}$ \\
\hline $\begin{array}{c}\text { Frequency, } \mathrm{f} \\
(\mathrm{Hz})\end{array}$ & 1.0 & 1.5 & 1.5 & 2.0 & 2.0 & 2.5 \\
\hline $\begin{array}{c}\text { Displacement } \\
\text { amplitude, } \mathrm{D} \\
(\mathrm{mm})\end{array}$ & 100 & 60 & 80 & 40 & 60 & 40 \\
\hline
\end{tabular}

Accelerometers were placed on the top surface of the shaketable and contents, while video recordings were made at 200 frames per second using a Phantom high-speed camera (Miro M310 model) shown in Figure 3b. Software developed by the Hedrick Lab [26] was used to track the circular markers

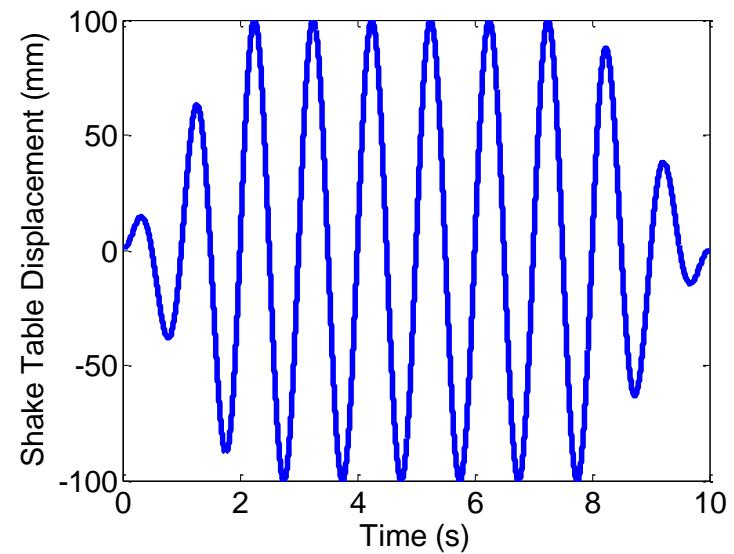

(a) attached to the content to obtain the displacement response of both with time. It should be noted that the use of one camera made it difficult to track any out-of-plane movement. However, visual inspections before and after each test showed that out-ofplane movement is negligible ( $<5 \mathrm{~mm}$ ) compared to the inplane response, and as such out-of-plane behaviour was not investigated further.

\section{FRICTION COEFFICIENT TEST RESULTS}

\section{Static Friction Coefficients}

The median $\mu_{s}$ assuming a lognormal distribution for each content, floor material, and applied mass considered are shown in Table 2. Note that an additional $10 \mathrm{~kg}$ was applied to the container as it was too light on its own to obtain $\mu_{s}$ data. Interestingly, the range of recorded $\mu_{s}$ for each content is relatively small, with the lognormal distribution dispersion being less than 0.05 .

Table 2: Median static friction coefficient results.

\begin{tabular}{|c|c|c|c|c|}
\hline \multirow[b]{2}{*}{ Content } & \multicolumn{2}{|c|}{ Carpet } & \multicolumn{2}{|c|}{ Vinyl } \\
\hline & $+0 \mathrm{~kg}$ & $+10 \mathrm{~kg}$ & $+0 \mathrm{~kg}$ & $+10 \mathrm{~kg}$ \\
\hline Desk 1 (D1) & 0.41 & 0.40 & 0.40 & 0.38 \\
\hline Desk 2 (D2) & 0.36 & 0.34 & 0.45 & 0.43 \\
\hline Drawer (MD) & 0.13 & 0.13 & 0.07 & 0.07 \\
\hline $\begin{array}{c}\text { Container (WC, } \\
+10 \mathrm{~kg})\end{array}$ & 0.25 & 0.24 & 0.13 & 0.13 \\
\hline
\end{tabular}

The ratio of the median $\mu_{s}$ between the carpet and vinyl flooring for the desks ranged from 0.96-1.25. This slight increase was due to the base of the desk tending to stick more to the vinyl surface, resulting in a similar or larger $\mu_{s}$ on vinyl flooring compared to carpet flooring.

The ratio of the median $\mu_{s}$ between the vinyl and carpet flooring for the contents on wheels ranged from 0.52-0.54. The difference between the response of these contents and the desks was that the friction resistance was from the wheel-axle interaction rather than the wheel-flooring surface. Thus, $\mu_{s}$ should theoretically be consistent for contents on wheels provided that wheel rotation governs the sliding response. However, the compression of the carpet due to the contents' weight resulted in the contents digging into the carpet, resulting in additional forces being required to overcome this effect in order for the content to slide, causing the recorded $\mu_{s}$ for contents with wheels on carpet flooring to be larger than that on vinyl.

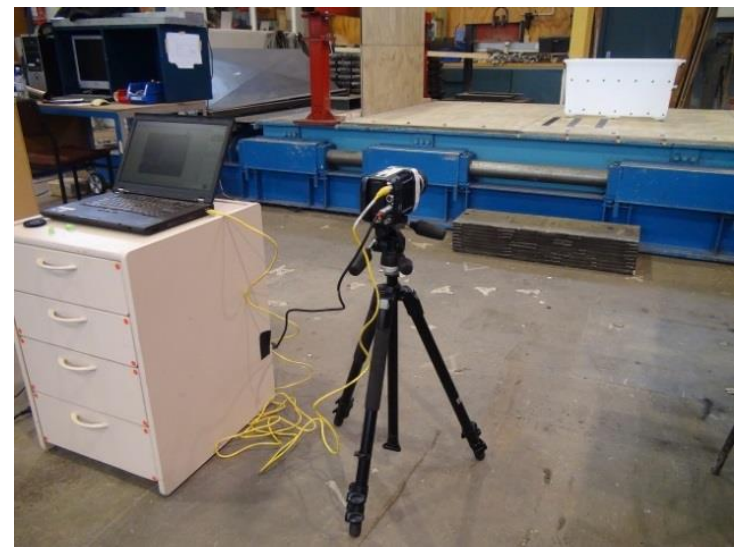

(b)

Figure 3: Dynamic excitation tests; (a) sample excitation (case 1), (b) camera setup. 
It was also shown in Table 2 that increasing the content mass by $10 \mathrm{~kg}$ (or an increase between 1.32 and 5.55 times) caused $\mu_{s}$ to decrease by $2 \%$ to $6 \%$ on average. This difference was in the range of experimental variability and is likely not significant.

\section{Kinetic Friction Coefficients}

The average $\mu_{k}$ from both kinetic pull-tests versus sliding displacement relationship is shown in Figure 4 for contents on carpet flooring. It can be seen that the sliding response was largely elastoplastic in nature. In each case, $\mu_{k}$ increased until approximately $\mu_{s}$ (from Table 2 ) before decreasing slightly. Interestingly, $\mu_{k}$ tends to be slightly larger in one direction than the other for desk 2, which could be due to uneven smoothness of its base surface as shown in Figure 5.

The influence of increasing mass for both desks (37-41\% increase for the $10 \mathrm{~kg}$ case, and $74-82 \%$ for the $20 \mathrm{~kg}$ case), and the drawer $(32 \%$ increase for the $10 \mathrm{~kg}$ case, and $64 \%$ for the 20 $\mathrm{kg}$ case), on $\mu_{k}$ are shown in Figures $4 \mathrm{a}$ to $4 \mathrm{c}$, respectively; while the influence of relative velocity on $\mu_{k}$ for both desks and the drawer are shown in Figures $4 \mathrm{~d}$ to $4 \mathrm{f}$, respectively. It was observed that there was a slight decrease in $\mu_{k}$ with increasing mass, which was similar to the $\mu_{s}$ findings from Table 2 . There was also an increase in $\mu_{k}$ with increasing relative velocity. However, both these effects were minor for the additional mass increase and range of relative velocity considered, and could potentially be due to experimental error.

Results using vinyl flooring are shown in Figure 6, where $\mu_{k}$ increased with decreasing mass or increasing relative velocity. There were no distinct localized peaks in $\mu_{k}$ when reversal occurs, resulting in $\mu_{s}$ being a reasonable estimate of $\mu_{k}$.

\section{DYNAMIC RESPONSE OF SHAKE-TABLE AND CONTENTS}

\section{General Sliding Behaviour}

This section examines the sliding behaviour of contents subjected to sinusoidal floor shaking. The response of Desk 2 on carpet flooring subjected to excitation Case 5 during the first four seconds of shaking is shown in Figure 7; where the total velocity response was obtained by differentiating the displacement response using a second order central difference approach. The contents' behaviour can be summarized as follows: (i) contents slid when the total floor acceleration at a given time, $a_{F T}(t)$, exceeded $\mu_{\mathrm{s}} g$; (ii) the content's total velocity varied approximately linearly between peaks; and (iii) sliding terminated when the content and shake-tables' velocities matched. This is consistent with Amonton and Columb's laws [14]. Similar observations were made for the other tests performed.

It was also observed that contents slid more in one direction than the other initially, despite the shake-table's total acceleration response being approximately symmetric. This was because the first sliding motion initiates when the static friction coefficient is exceeded; while the reverse sliding motion is immediately triggered when the content's velocity matches that of the floor, provided the static friction coefficient is already exceeded in the reverse direction. This difference causes the content to move out-of-phase to the floor initially, resulting in transient sliding motion. The sliding response does become more symmetric after several cycles as shown by the decreasing difference in duration between the sliding displacement peaks.

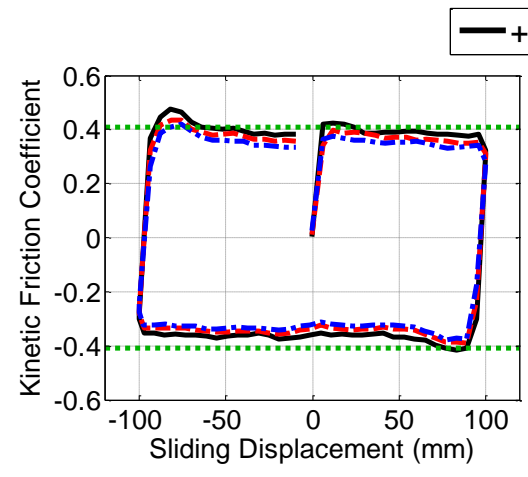

(a) Desk 1 (varying mass, $3 \mathrm{~mm} / \mathrm{s}$ )

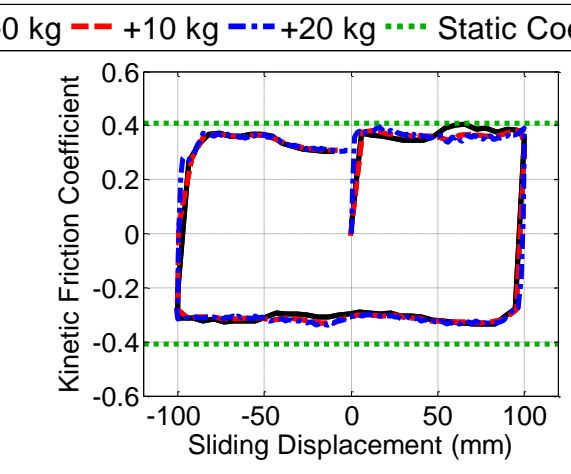

(b) Desk 2 (varying mass, $3 \mathrm{~mm} / \mathrm{s}$ )

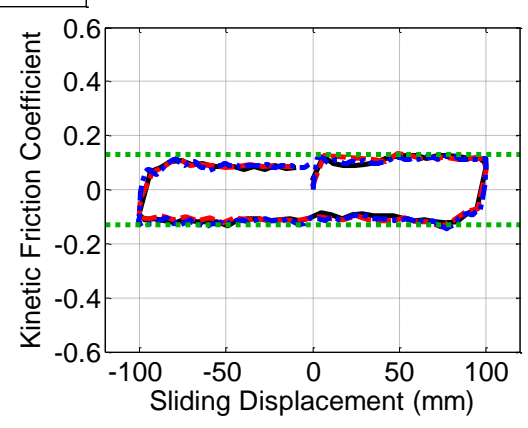

(c) Drawer (varying mass, $3 \mathrm{~mm} / \mathrm{s}$ )

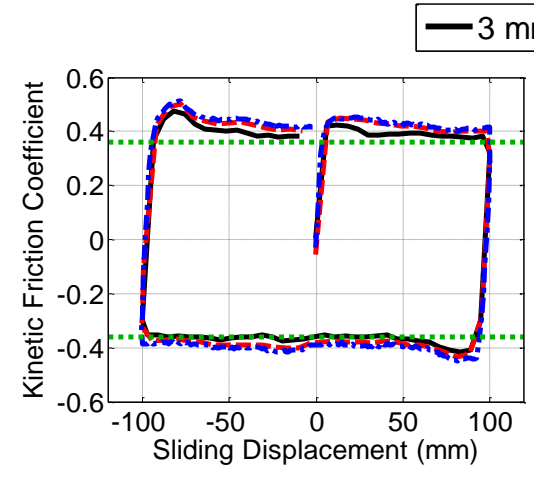

(d) Desk 1 (varying disp rate, $+0 \mathrm{~kg}$ )

$3 \mathrm{~mm} / \mathrm{s}=-7 \mathrm{~mm} / \mathrm{s}-\cdot-10 \mathrm{~mm} / \mathrm{s}$ " ". Static Coefficient

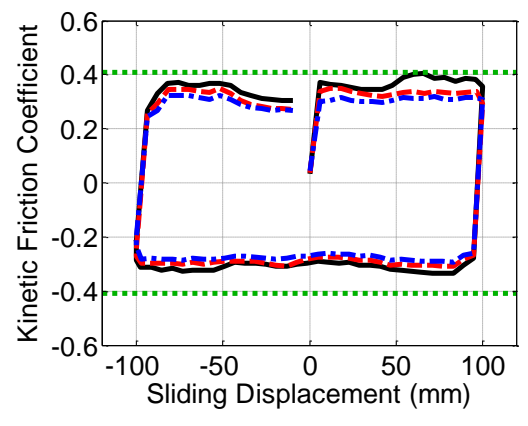

(e) Desk 2 (varying disp rate, $+0 \mathrm{~kg}$ )

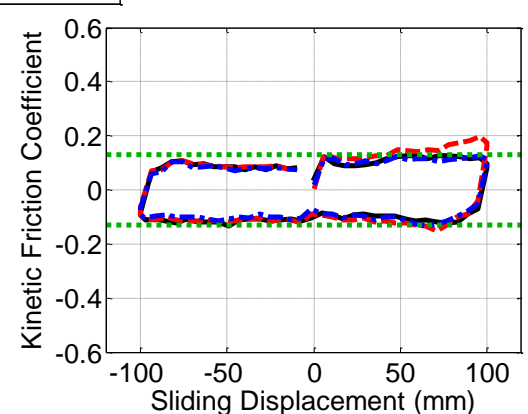

(f) Drawer (varying disp rate, $+0 \mathrm{~kg}$ )

Figure 4: Average kinetic friction coefficient versus sliding displacement relationship with varying content mass and floor displacement rates (carpet flooring). 
Note that while the recorded shake-table displacement matched the input motions described in Figure 3a, the resulting shakingtable acceleration response was not sinusoidal in shape. One reason could be due to stick-slip of the shake-table bearings which resulted in vibrations and high frequency accelerations on both the shake table and the content. An alternate explanation is that this could also be due to an out-of-tune hydraulic control system. This can cause errors during (i) estimation of the friction coefficients during sliding using the acceleration results from the dynamic tests, and (ii) validation of numerical approaches in later parts of this study.

\section{Estimation of the Kinetic Friction Coefficient from Dynamic Floor Excitations}

The kinetic friction coefficient, $\mu_{k}$, was estimated from the sinusoidal shake-table tests. The $\mu_{k}$ versus sliding displacement relationship for Desk 2 on carpet flooring using the Case 5 excitation is shown in Figure 8a. It may be seen that $\mu_{k}$ had significant variation with sliding displacement. In addition, $\mu_{k}$ was up to $71 \%$ larger than the value of $\mu_{s}$ obtained from pulltests. This could be due to (i) vibration of Desk 2 which was observed but difficult to measure, (ii) inherent variation in $\mu_{k}$ across the flooring and/or contact surface area, and (iii) issues with the shake table inputs as discussed previously. Due to this, reasonable $\mu_{k}-v_{C R F}$ relationships could not be obtained, and comparisons with past research [17-20] could not be made.

Given the variation in the accelerometer readings discussed previously, the average $\mu_{k}$ during each sliding excursion (i.e. a single back-and-forth motion), $\mu_{k, a v g}$, was computed instead.
This was done by calculating the slope between each peak of the content's total velocity response and dividing it by acceleration due to gravity, $g$. Computed $\mu_{k, \text { avg }}$ values following this approach are shown in Figure $8 b$, where $\mu_{k, a v g}$ was (i) reasonably consistent with each sliding excursion, and (ii) was well approximated by $\mu_{s}$ for this case.

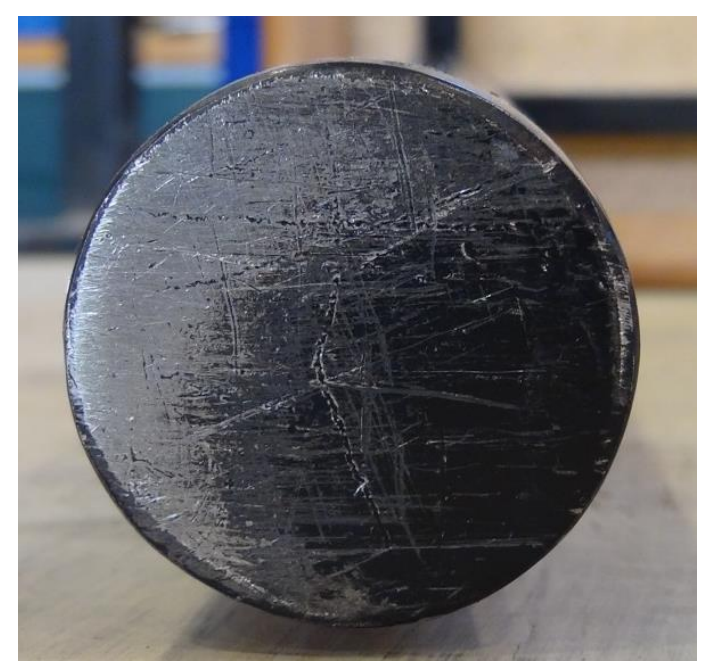

Figure 5: Uneven smoothness of the base of Desk 2 (similarly observed on all legs).

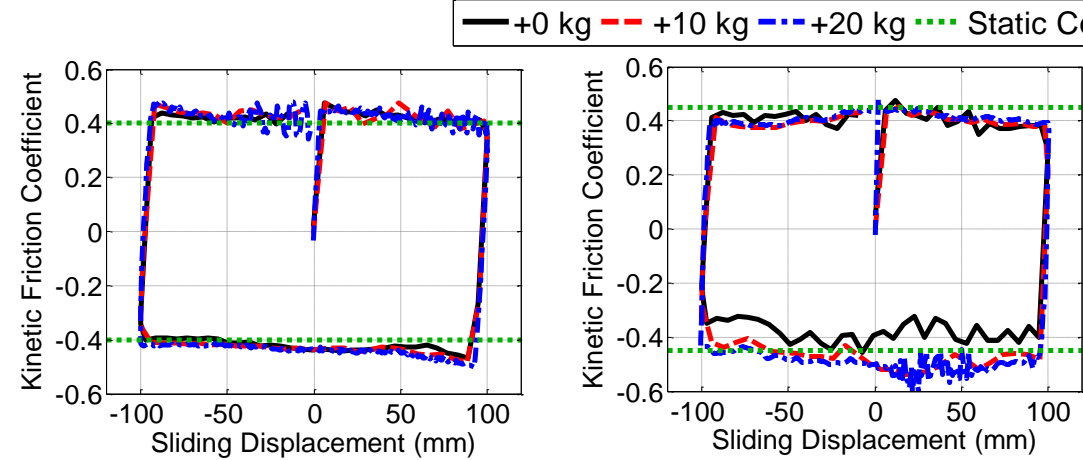

(a) Desk 1 (varying mass, $3 \mathrm{~mm} / \mathrm{s}$ )

(b) Desk 2 (varying mass, $3 \mathrm{~mm} / \mathrm{s}$ )

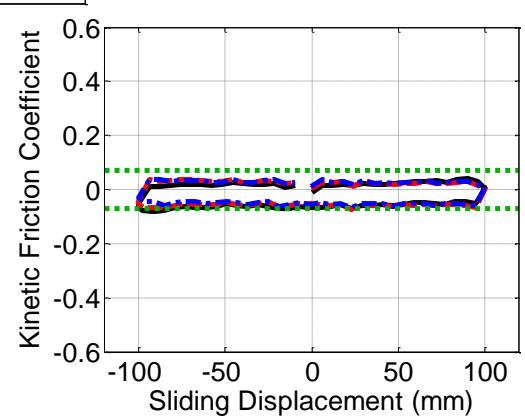

(c) Drawer (varying mass, $3 \mathrm{~mm} / \mathrm{s}$ )

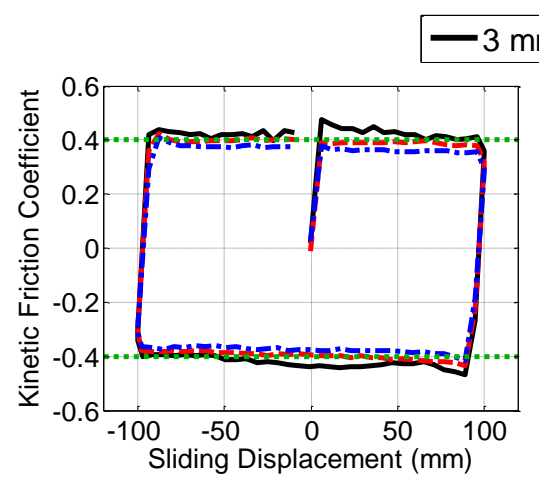

(d) Desk 1 (varying disp rate, +0kg)

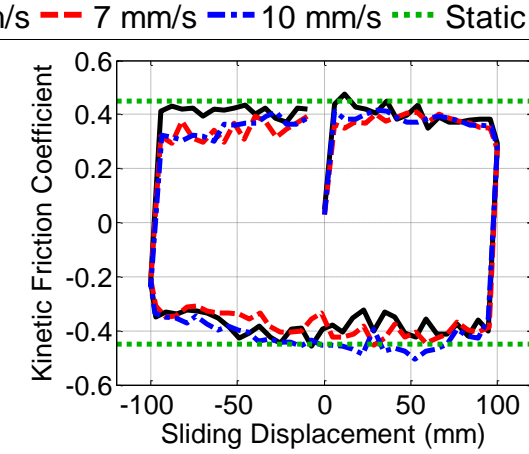

(e) Desk 2 (varying disp rate, $+0 \mathrm{~kg}$ )

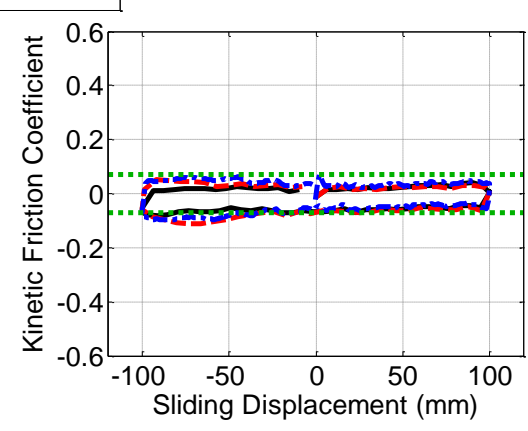

(f) Drawer (varying disp rate, $+0 \mathrm{~kg}$ )

Figure 6: Average kinetic friction coefficient versus sliding displacement relationship with varying content mass and floor displacement rates (vinyl flooring). 

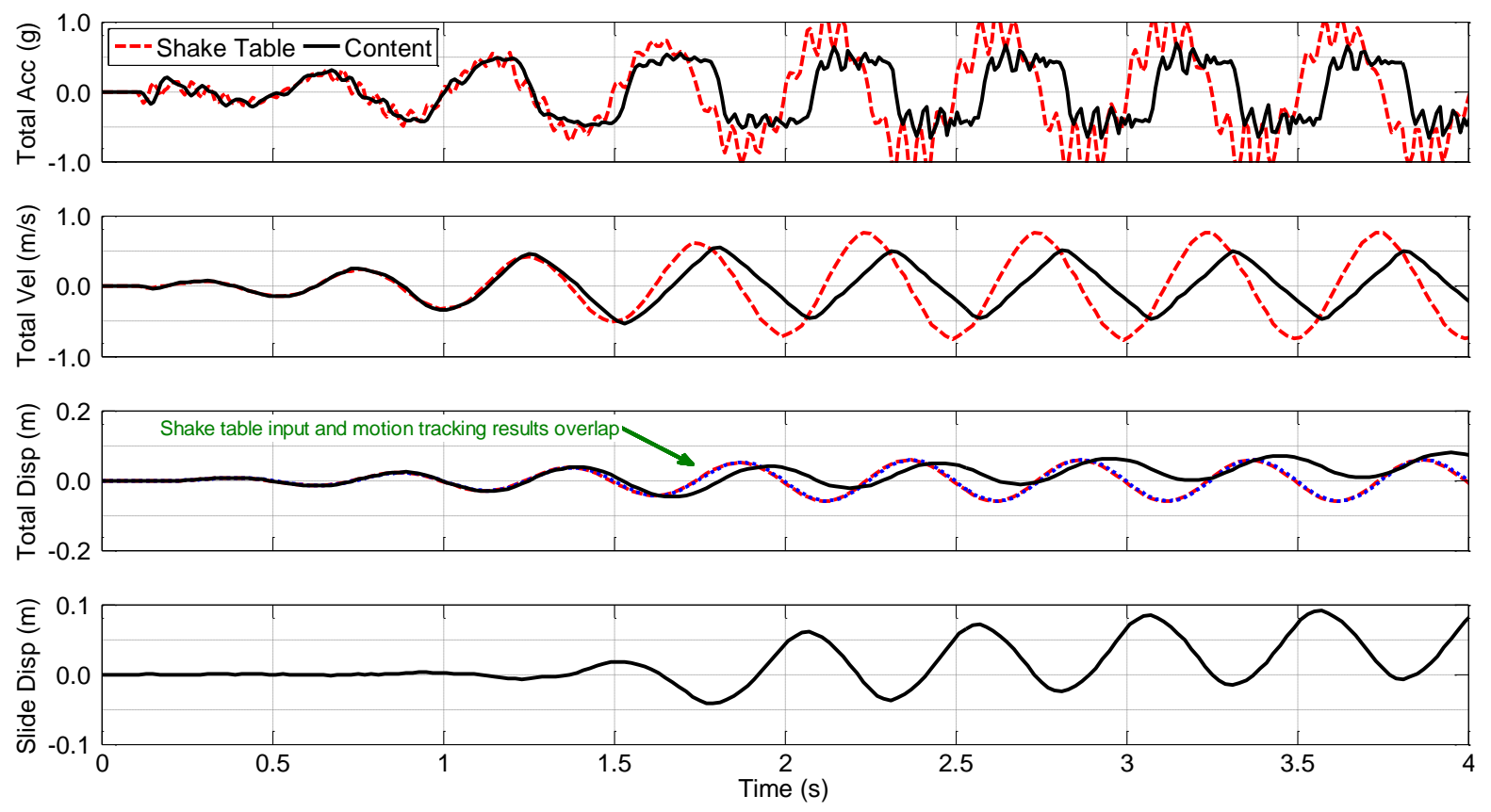

Figure 7: Shake table and Desk 2 response on carpet flooring $(f=2.0 \mathrm{~Hz}, \mathrm{D}=60 \mathrm{~mm})$ - first 4 seconds.

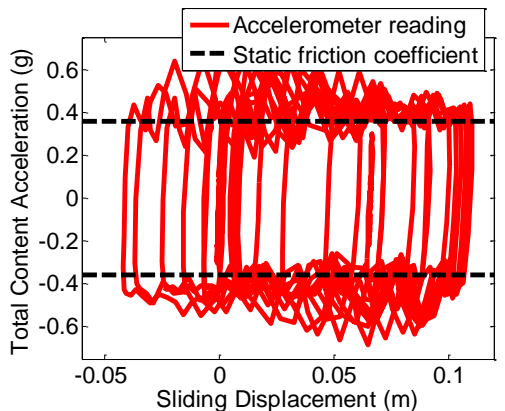

(a)

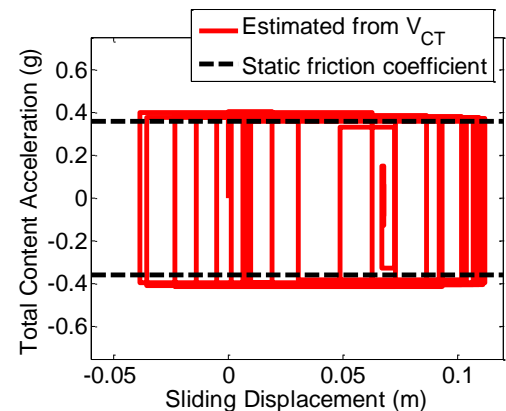

(b)

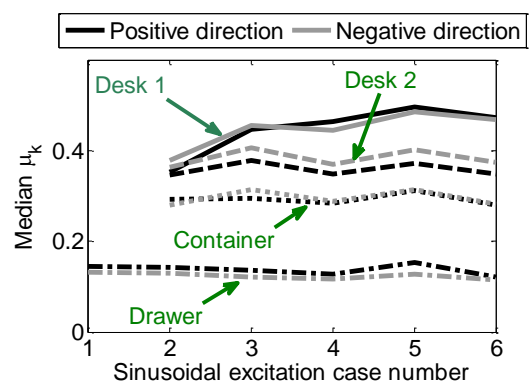

(c)

Figure 8: Kinetic friction coefficients; (a) variation using accelerometer reading (Desk 2 on carpet using Case 5), (b) average estimate (Desk 2 on carpet using Case 5), and (c) median of average estimate for differing cases on carpet flooring.

The median $\mu_{k, \text { avg }}$ for all contents on carpet flooring are shown in Figure 8c, where apart from Desk 1, the median $\mu_{k}$ did not vary by more than $10 \%$ between the different sinusoidal cases. This indicated that while $\mu_{k}$ possibly varied with $v_{C R F}(t)$ based on results from Figure 4, its effect was not significant on average. The overall magnitude of $\mu_{k}$,avg in both directions were similar, with desk 2 being the only case with a noticeable difference in both directions due to the uneven smoothness of its base as discussed previously considering Figure 5. Similar findings were obtained for the vinyl flooring cases.

The median, $x_{m}$, and dispersion, $\zeta$, of $\mu_{k, a v g}$ assuming a lognormal distribution are shown Table 3. The median $\mu_{k, \text { avg }}$ was between 0.98-1.17 times the median $\mu_{s}(+0 \mathrm{~kg}$ case) recorded from the static friction tests for contents on carpet flooring. These findings do contradict existing studies $[16 ; 19$; 21] which found that $\mu_{k}$ is generally lower than $\mu_{s}$. This difference however could be attributed to the base of the content having to move through the carpet fibres rather than simply sliding on it, which causes additional drag forces to resist movement.
In the case of vinyl flooring (Table 4), the ratio between the median $\mu_{k, \text { avg }}$ to the median $\mu_{s}$ was between $0.57-1.08$. These findings are more similar to those from existing studies $[16 ; 19$; 21] since there are no additional drag forces from the flooring material in this case. This resulted in contents on vinyl flooring having lower $\mu_{k, \text { avg }}$ compared to those on carpet flooring despite having a larger $\mu_{s}$ for the desks.

Note that the median $\mu_{k, \text { avg }}$ for the desks and drawer on vinyl flooring was just $57-75 \%$ of $\mu_{s}$ obtained from the static friction test. This contrasted $\mu_{k}$ obtained from kinetic friction tests in Figure 6 . This is likely due to the relative acceleration between the content and the flooring surface being zero in the kinetic friction pull tests due to the flooring surface being displaced at constant velocity. In the shake-table test and in reality, the relative acceleration is unlikely to remain zero during sliding as shown in Figure 7 . Therefore, the $\mu_{k, \text { avg }}$ values obtained from the dynamic test results were assumed to be more realistic, and were used for numerical validation later in this paper 
Table 3: Kinetic friction coefficient results from dynamic tests on carpet flooring (average during sliding).

\begin{tabular}{cccc} 
Content & $\boldsymbol{x}_{\boldsymbol{m}}$ & $\boldsymbol{\zeta}$ & $\%$ of $\boldsymbol{\mu}_{\boldsymbol{s}}(\mathbf{+} \mathbf{0 k g})$ \\
\hline Desk 1 & 0.45 & 0.108 & 1.10 \\
\hline Desk 2 & 0.37 & 0.063 & 1.03 \\
\hline Drawer & 0.13 & 0.186 & 0.98 \\
\hline Container & 0.29 & 0.125 & 1.17
\end{tabular}

\section{Table 4: Kinetic friction coefficient results from dynamic tests on vinyl flooring (average during sliding).}

\begin{tabular}{cccc} 
Content & $\boldsymbol{x}_{\boldsymbol{m}}$ & $\boldsymbol{\zeta}$ & $\%$ of $\boldsymbol{\mu}_{\boldsymbol{s}}(+\mathbf{0 k g})$ \\
\hline Desk 1 & 0.30 & 0.110 & 0.75 \\
\hline Desk 2 & 0.30 & 0.197 & 0.67 \\
\hline Drawer & 0.04 & 0.326 & 0.57 \\
\hline Container & 0.14 & 0.057 & 1.08 \\
\hline
\end{tabular}

Effect of Total Floor Acceleration Amplitude and Frequency

The response of Desk 2 subjected to sinusoidal excitation Case 5 and Case 6 were compared to observe the influence of the floor motion's frequency. Both cases have nearly identical peak total floor (shake-table) accelerations, $A_{F T}$, which were $0.96 \mathrm{~g}$ and $1.01 \mathrm{~g}$ for cases 5 and 6 , respectively. Despite this, the maximum, residual, and individual sliding excursion displacements shown in Figure 9a were lower by $40 \%$ for Case 6 compared to Case 5; demonstrating that $A_{F T}$ alone is not a good indicator of the extent of the maximum sliding displacement. This was further emphasized by the maximum sliding displacement versus $A_{F T}$ plot in Figure $9 \mathrm{~b}$ for all contents on both flooring materials, where there were no clear trends between the extent of sliding and $A_{F T}$ alone. For example, the sliding response of the drawer (MD) on vinyl flooring was relatively constant despite $A_{F T}$ ranging from $0.4 \mathrm{~g}$ to $1.0 \mathrm{~g}$.

An alternate parameter proposed here for comparisons with the peak sliding displacement is the Modified Peak Total Floor Velocity, $M V_{F T}$, which was used to approximate the content's velocity relative to the floor. This accounts for the fact that the sliding displacement was dependent on the content's relative velocity to the floor. Assuming that the content and floor acceleration was constant with time, the expression for $M V_{F T}$ is that shown in Equation 2:

$$
M V_{F T}=V_{F T}\left\langle 1-\frac{\mu g}{A_{F T}}\right\rangle
$$

where $\quad V_{F T}=$ shake-table's peak total velocity.

It can be seen from the maximum sliding displacement versus $M V_{F T}$ plot in Figure 9c that there is a much clearer increasing trend for all cases compared to considering $A_{F T}$ on its own when $M V_{F T}$ is less than $0.4 \mathrm{~m} / \mathrm{s}$. While the spread is much wider at larger values of $M V_{F T}$, the maximum sliding displacement does still generally increase overall. This indicates that $V_{F T}$ is also important.

To explain the limitations of considering $A_{F T}$ alone, the generic content and floor total acceleration and total velocity curves in Figures 10a and 10b, respectively, are examined. These curves were based on a single sinusoidal floor response cycle similar to that from Figure 7; where, $\omega_{T}$ is the total floor response frequency, and $T_{0}$ and $T_{e}$ are the times at which content sliding initiates and ends, respectively. The shaded area in Figure 10b equals a single sliding excursion displacement. If $A_{F T}$ and $\mu_{k}$ were kept constant but $\omega_{T}$ was decreased, this would result in (i) the content sliding for a longer duration, and (ii) the velocity amplitude increasing. Both of these would cause the sliding excursion displacement to increase. This explains the reason behind Desk 2 on carpet flooring experiencing more severe response when subjected to sinusoidal excitation Case 5 in Figure 9a, and also demonstrates the importance of $\omega_{T}$. However, for more complex dynamic shaking inputs where there is no one unique frequency, $\omega_{T}$ would be difficult to obtain. Therefore, $A_{F T} / V_{F T}$ can be used as a substitute for $\omega_{T}$ instead since $V_{F T}$ is dependent on both the total floor acceleration response and excitation frequency.

While the importance of frequency was obvious for sinusoidal floor motions, there is practical significance for more realistic excitations. For example, stiffer buildings generally experience larger total floor accelerations compared to more flexible buildings, but would have a higher shaking frequency. Therefore, contents within stiffer buildings may not necessarily experience more severe sliding response. There is a limit to this as the decreased accelerations in very flexible buildings may prevent content sliding from occurring in the first place. The importance of stiffness is re-examined later in this study.

\section{VALIDATION OF CONTENT SLIDING ANALYSES}

The prior sections showed that the contents' overall sliding behaviour (Figure 7) and $\mu_{k, a v g}$ trends (Figure 8b) were consistent with numerical modelling assumptions from previous studies. It was however evident from Figure 8a that variation in $\mu_{k}$ exist, which may cause numerical findings to differ from experimental findings. As such, validation of numerical models was required to observe the significance of this effect. Content sliding analyses were performed using Newmark's integration scheme [27]; where $a_{C T}(t)$ was defined using Equation 1 [15], and the shake-table's total acceleration response history recorded from the dynamic tests was inputted as $a_{F T}(t)$. The discontinuity in Equation 1 was addressed by decreasing the analysis time-step until the numerical results are consistent; in which a time-step of $0.001 \mathrm{~s}$ was found to be sufficient.

The comparison between the recorded sliding displacement response from the shake-table test and that from analyses for Desk 2 on carpet flooring subjected to Case 5 sinusoidal loading is shown in Figure 11a using the median $\mu_{s}$ and $\mu_{k, \text { avg }}$ from Tables 2 and 3, respectively. There is good agreement between the two cases before divergence occurred around the seventh cycle, resulting in the maximum and residual sliding displacements being over-predicted by $32 \%$ and $64 \%$, respectively. While not shown here, divergence between experimental and numerical results also occurred for majority of cases considered; though the number of cycles at which this occurred, and the extent of divergence, varied.

The discrepancy between the numerical and experimental results could be due to use of $\mu_{k, \text { avg }}$, which results in the potential variation in $\mu_{k}$ to not be properly considered. In addition, the inaccuracies in the acceleration recordings due to issues with the shake table inputs as discussed previously potentially meant that the total acceleration response inputted into the numerical models may not be the same as that felt by the content during testing. 


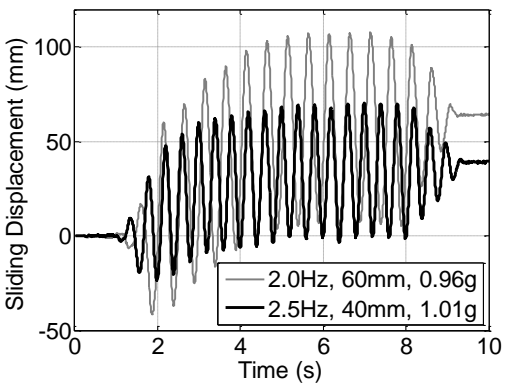

(a)

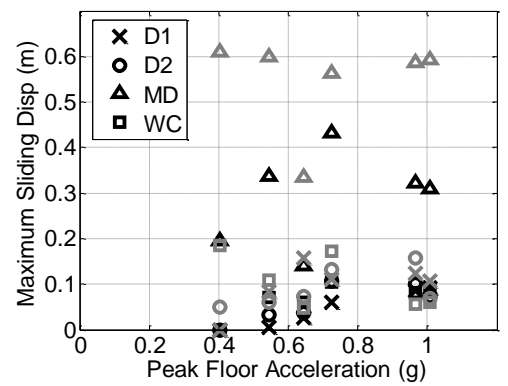

(b)

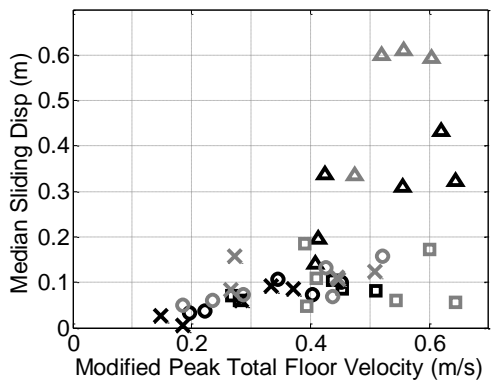

(c)

Figure 9: Influence of floor excitation frequency on median displacement of sliding excursions; (a) Case 5 versus Case 6 for Desk 2 on carpet flooring, (b) maximum sliding displacement-AFT, (c) maximum sliding displacement-MVTF [dark markers in (b) and (c) for carpet, light for vinyl].

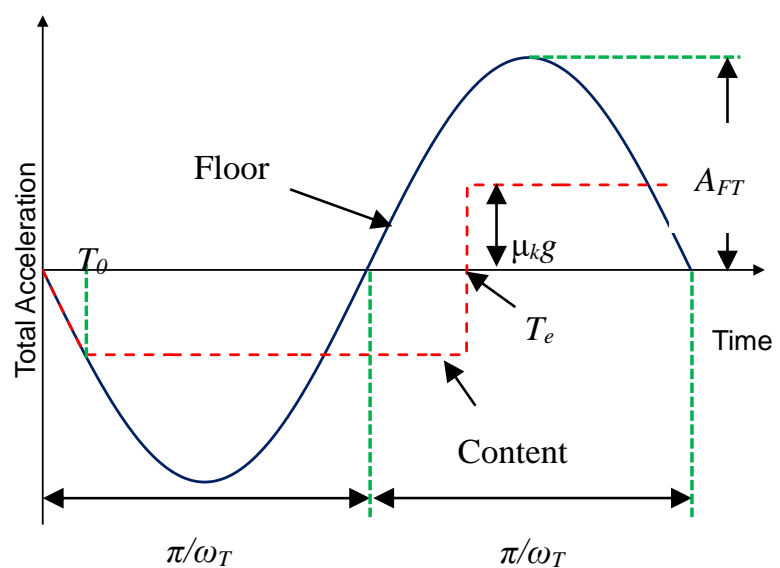

(a)

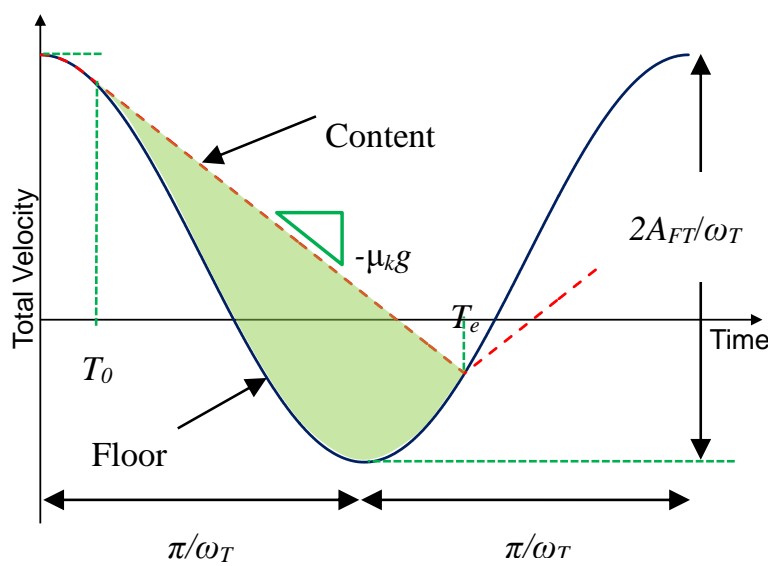

(b)

Figure 10: Effect of frequency on sliding excursion displacement for contents subjected to sinusoidal floor motion; (a) total acceleration response, (b) total velocity response.

This process was repeated for all dynamic experimental tests performed. The ratio between the maximum sliding displacement obtained from numerical analysis against that from experiments for carpet and vinyl flooring are shown in Figures $11 \mathrm{~b}$ and $11 \mathrm{c}$, respectively. It can be seen that the numerical approach does not always over-predict the content's sliding response. Furthermore, sizeable errors were observed on a case-by-case basis with the ratio ranging between 0.3 to 3.0 . There are, however, no obvious trends in the degree of under or over-prediction with furniture type. As such, the median ratios were calculated considering all furniture for each sinusoidal excitation and flooring material case. This median ratio ranged between $0.58-1.35$ for carpet flooring, and 0.95-1.32 for vinyl flooring, as observed in Figures $11 \mathrm{~b}$ and 11c, respectively. The average of all sinusoidal excitation cases, excluding Case 6 on carpet flooring which had a ratio noticeably lower than other cases, were 1.05 and 1.06 for carpet and vinyl flooring, respectively. Based on these observations, the predictions may be reasonable on average if multiple excitations are considered.

\section{NUMERICAL MODELLING APPLICATIONS}

\section{Case Study Details}

To demonstrate the usefulness of numerical approaches, a preliminary numerical case-study examining the sliding response of contents resting on top of a single-degree-offreedom structure was performed to observe (i) the effect of building stiffness on content sliding response, and (ii) the need to consider both $\mu_{s}$ and $\mu_{k}$ in analyses. The buildings have elastic fundamental periods ranging from $0.01 \mathrm{~s}$ to $1.50 \mathrm{~s}$; and were designed for Wellington, New Zealand, subsoil class C conditions with a force reduction factor of 2.0.

The $10 \%$ probability of exceedance in 50 year uniform hazard spectra (UHS) used for design was obtained from OpenSHA [28] using New Zealand-specific rupture forecast models [29] and attenuation equations [30]. The ground motion used in analyses were selected following the Generalized Conditioning Intensity Approach (GCIM) [31], with the spectral acceleration at $0.50 \mathrm{~s}$ being selected as the conditioning intensity measure. The other intensity measures selected, and their weighting factor, followed that used by Bradley [32].

Only the drawer on vinyl flooring $\left(\mu_{s}=0.066, \mu_{k, a v g}=0.041\right)$ was analysed. The numerical analyses were repeated three times considering (i) $\mu_{s}$ only, (ii) $\mu_{k, \text { avg }}$ only, and (iii) both $\mu_{s}$ and $\mu_{k, \text { avg. }}$.

\section{Effect of Building Stiffness}

The building's median peak total floor acceleration response, $A_{F T}$, peaked at $0.25 \mathrm{~s}$ before decreasing with period as shown in Figure 12a. Despite the $0.25 \mathrm{~s}$ building having the largest median $A_{F T}$, it did not have the largest maximum sliding displacement, $\delta s$, when both $\mu_{s}$ and $\mu_{k, \text { avg }}$ were considered, as shown in Figure $12 \mathrm{~b}$. Instead, the median, $16^{\text {th }}$, and $84^{\text {th }}$ percentile $\delta s$ peaked at $1.25 \mathrm{~s}$.

The importance of floor shaking frequency is illustrated in Figure 13 considering the response of contents within two 
buildings, one with period, $T$, of $0.25 \mathrm{~s}$ and another with $T=$ $1.25 \mathrm{~s}$, using one of the records from the selected suite. While the $A_{F T}$ for the $0.25 \mathrm{~s}$ building $(0.804 \mathrm{~g})$ was larger than that of the $1.25 \mathrm{~s}$ building $(0.282 \mathrm{~g})$; the higher shaking frequency of the $0.25 \mathrm{~s}$ case in Figure 13a resulted in the duration of each acceleration peak being smaller than for the $1.25 \mathrm{~s}$ case in Figure $13 \mathrm{~b}$. This resulted in the maximum sliding displacement for the $0.25 \mathrm{~s}$ case $(0.205 \mathrm{~m})$ being 4.0 times smaller than that of the $1.25 \mathrm{~s}$ case in Figure 13c. This matched the discussions from Figure 10, and demonstrates the importance of shaking frequency.

These results highlighted that the sliding response of building contents may actually decrease when a building's stiffness is increased, despite its higher acceleration response. This finding may also apply to other non-brittle acceleration-sensitive components, such as unanchored rocking contents. However, brittle components such as fixed ceiling systems may still be severely affected by the higher accelerations in stiffer buildings.

\section{Consideration of Friction Coefficients in Numerical Analyses}

The ratio between the maximum sliding displacements considering (i) $\mu_{s}$ only, and (ii) $\mu_{k, a v g}$ only, against that considering both $\mu_{s}$ and $\mu_{k, \text { avg }}$ using Equation 1, are shown in
Figures $14 \mathrm{a}$ and $14 \mathrm{~b}$ respectively. It can be seen that the median ratio ranged from 0.56 to 0.92 , while the $16^{\text {th }}$ percentile ratio ranged from 0.33 to 0.76 , when considering $\mu_{\mathrm{s}}$ only. This demonstrated that considering $\mu_{\mathrm{s}}$ only generally produced nonconservative predictions. In contrast, the median ratio considering $\mu_{\text {kavg }}$ only ranged from 0.96 to 1.00 . As such, analysis considering only $\mu_{k, \text { avg }}$ may be performed in place of one considering both $\mu_{s}$ and $\mu_{k, \text { avg }}$ for simplicity.

One interesting observation between the two cases is that the spread considering only $\mu_{s}$ is greater compared to considering only $\mu_{k, a v g}$. If Figure $10 \mathrm{~b}$ is re-examined, it can be seen that the extent of content sliding, which is the shaded area between the content and floor response velocity curves, is highly dependent on the slope $\mu_{k, a v g} g$. While sliding initiates earlier considering only $\mu_{k, a v g}$, the shaded area shape would still be similar to considering both $\mu_{s}$ and $\mu_{k}$,avg, resulting in smaller spread. In contrast, considering $\mu_{\mathrm{s}}$ on its own would result in a steeper slope which would decrease both the amplitude of the content's velocity relative to the floor and the duration of sliding. This results in lower sliding displacements with each individual sliding excursion. As this affects both the back-and-forth direction of sliding, this can at times result in an over-prediction of sliding response, though in most cases the amount of sliding is lower. This results in the larger spread of ratios observed when considering only $\mu_{s}$.

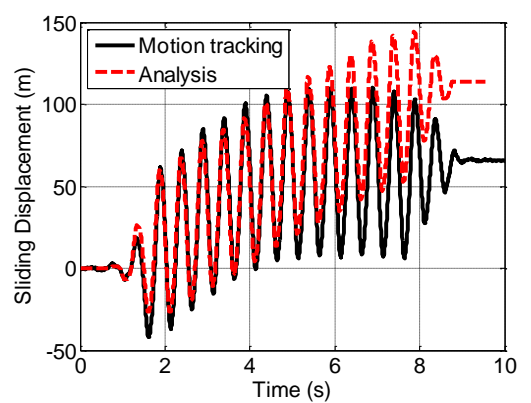

(a)

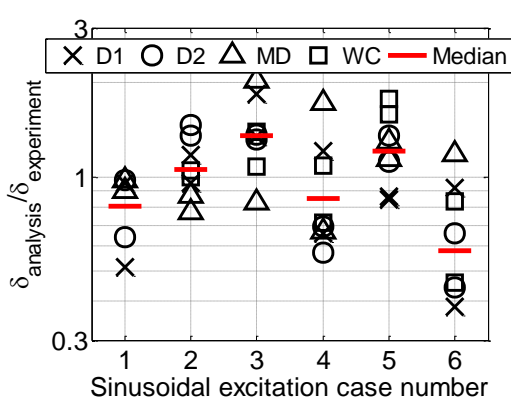

(b)

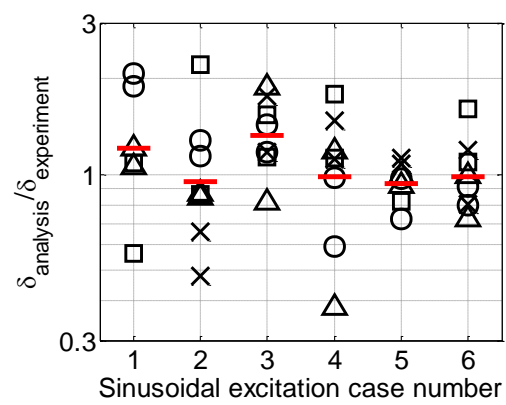

(c)

Figure 11: Comparison of experimental and analytical sliding displacement history; (a) $f=2.0 \mathrm{~Hz}, \mathrm{D}=60 \mathrm{~mm}$ carpet flooring, (b) maximum displacement ratio (analytical versus experimental) for carpet flooring, (c) maximum displacement ratio for vinyl flooring.

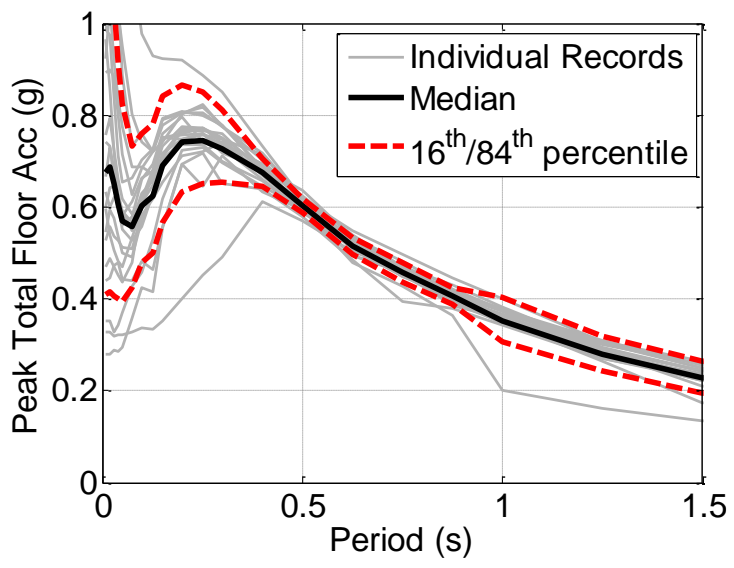

(a)

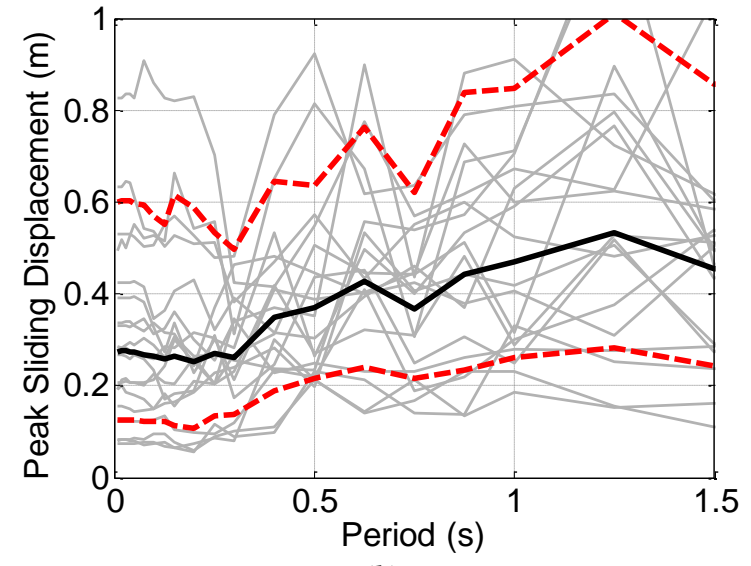

(b)

Figure 12: Effect of building stiffness case study; (a) peak total floor acceleration response, and (b) peak sliding displacement response considering both $\mu_{s}$ and $\mu_{k, \text { avg. }}$ 
(a)

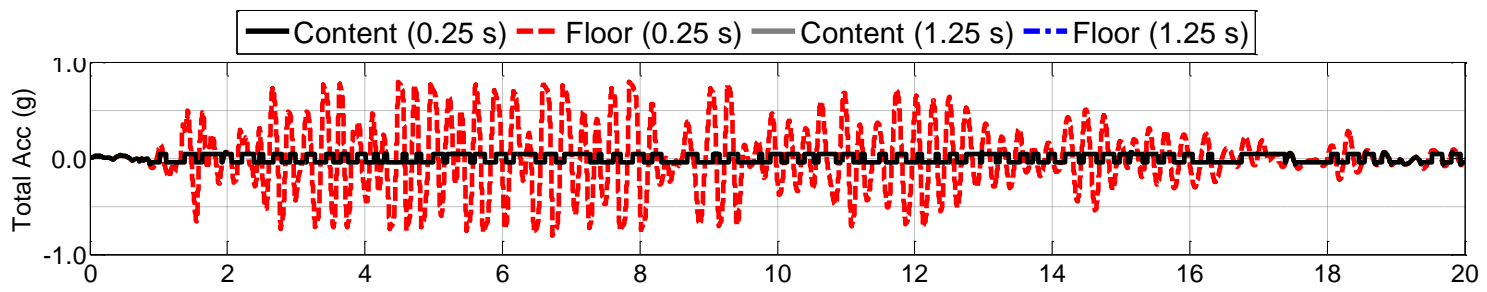

(b)

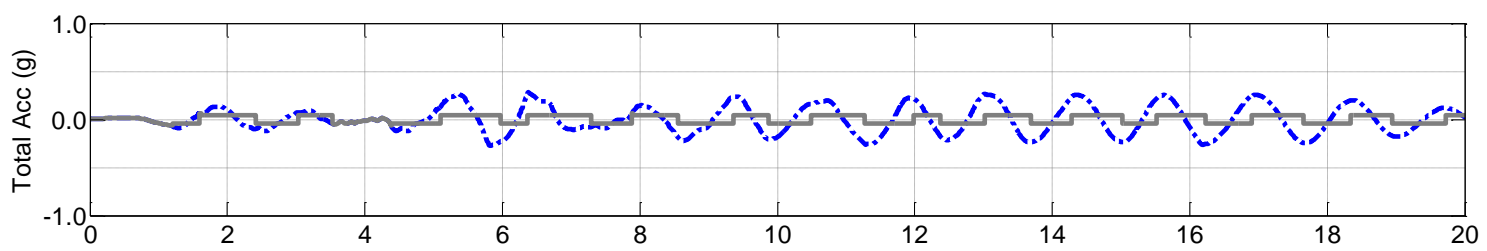

(c)

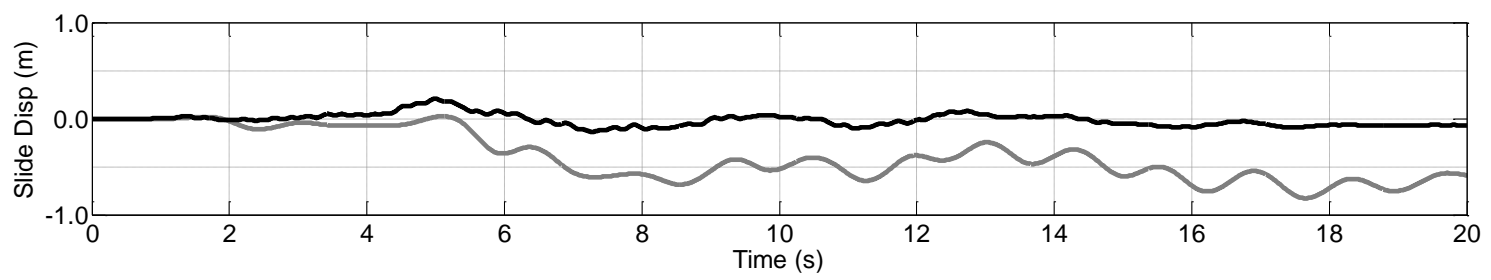

Figure 13: Effect of single-storey building stiffness on content sliding response; (a) content and floor acceleration response $(0.25 \mathrm{~s}),(\mathrm{b})$ content and floor total acceleration response $(1.25 \mathrm{~s})$, and (c) content sliding displacement response for both $0.25 s$ and $1.25 s$ cases.

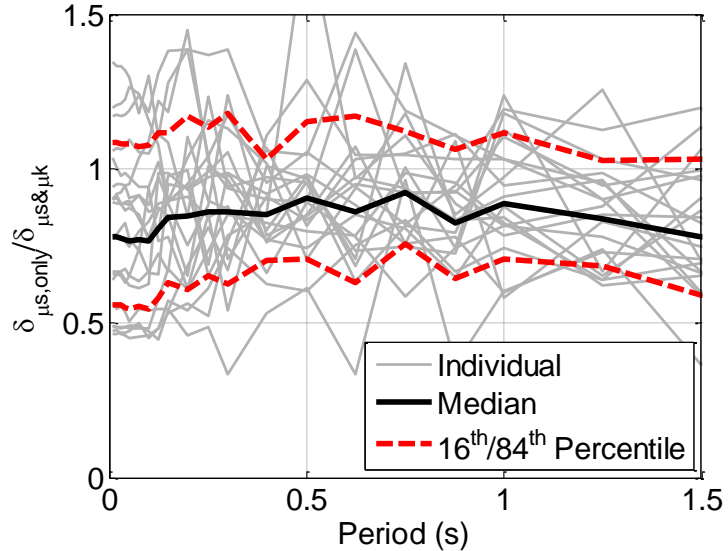

(a)

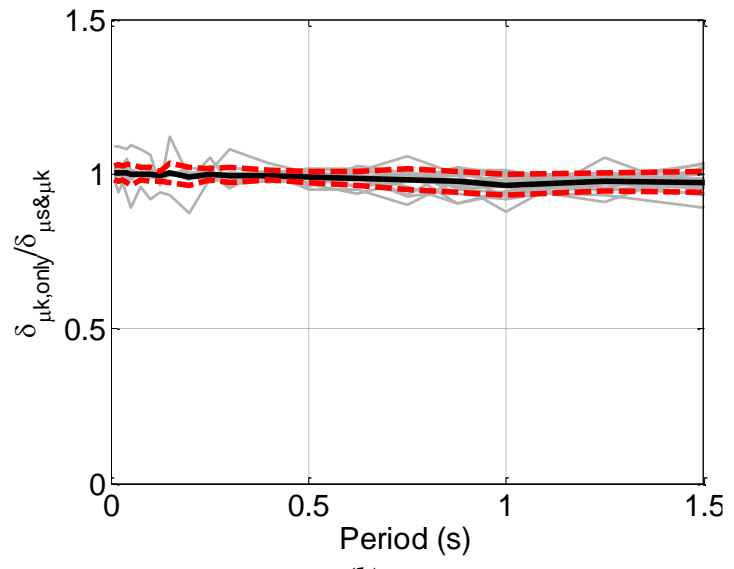

(b)

Figure 14: Ratio between maximum sliding displacement obtained from analyses considering $(a) \mu=\mu_{s}$, or $(b) \mu=\mu_{k}$, against that considering both $\mu_{\mathrm{s}}$ and $\mu_{\mathrm{k}}$.

\section{CONCLUSIONS}

Static and kinetic friction tests, and shake-table tests using sinusoidal floor motions, of office-type furniture on carpet and vinyl flooring were performed. It was found that:

1. Static friction tests showed that the static coefficient of friction, $\mu_{s}$, ranged between $0.13-0.30$ and $0.07-0.13$ for contents with wheels, and 0.36-0.45 and 0.39-0.45 for contents without wheels, on carpet and vinyl flooring, respectively. The contents' mass had negligible effect on $\mu_{s}$.

2. The average kinetic coefficient of friction, $\mu_{k, \text { avg }}$, obtained from shake-table tests using sinusoidal motion was approximately equal to, or slightly larger than, $\mu_{s}$ for contents on carpet flooring; and was up to $38 \%$ lower on vinyl flooring. Kinetic friction tests showed varying mass and the content's velocity relative to the floor had marginal effect on $\mu_{k}$.

3. Content sliding analyses matched shake-table test results with an average error of 5\% considering all cases, though large errors by up to a factor of 3 were observed on a caseby-case basis.
4. AFT on its own was found to be an insufficient descriptor of the extent of content sliding. Consideration of peak total floor velocity, $V_{F T}$, together with peak total floor acceleration, $A_{F T}$, was more sufficient.

5. Using numerical approaches considering $\mu_{k, \text { avg }}$ only resulted in almost identical results to considering both $\mu_{s}$ and $\mu_{k, \text { avg }}$; indicating that $\mu_{s}$ may not need to be considered in analysis for simplicity.

\section{ACKNOWLEDGEMENTS}

The authors would like to thank MBIE Natural Hazards Platform for funding the project; John Maley and Alan Poynter for their assistance in setting up and running the shake table tests; the Geotechnical Laboratory for allowing usage of the high speed camera; the University Warehouse staff for supplying the furniture used in the experiments; and the University of Canterbury, the New Zealand Society for Earthquake Engineering, and the New Zealand Earthquake Commission for providing financial support at various stages of the first author's PhD candidacy. The authors would also like to acknowledge the reviewers of this paper who had provided 
insightful discussions and suggested some alternate explanations for test observations.

\section{REFERENCES}

1. FEMA E-74 (2012). "Reducing the Risks of Nonstructural Earthquake Damage - A Practical Guide". FEMA, USA.

2. Sato E, Furukawa S, Kakehi A and Nakashima M (2011). "Full-scale shaking table test for examination of safety and functionality of base-isolated medical facilities". Earthquake Engineering and Structural Dynamics, 40(13): 1435-1453.

3. Nagao T, Kagano H and Hamaguchi K (2012). "Full-scale shaking table test on furnitures subjected to long-period earthquake motions". 15th World Conference on Earthquake Engineering, Lisbon, Portugal.

4. Dhakal RP (2010). "Damage to Non-Structural Components and Contents in 2010 Darfield Earthquake". Bulleting of the NZSEE, 43(4): 404-412.

5. Okada S, Nachi N and Endo T (2012). "Seismic Assessment Method for Indoor Injury Risk and Its Application". 15th World Conference on Earthquake Engineering, Lisbon, Portugal. pp8.

6. Yeow TZ, MacRae GA, Dhakal RP and Bradley BA (2013). "Probabilistic seismic indoor injury estimation". NZSEE Annual Conference, Wellington, NZ.

7. Kaneko M, Hayashi Y and Tamura K (1999). "Evaluation of Sliding Displacement of Furniture during Earthquake by using Revised Formula to Estimate Sliding Displacement of Furniture". Technical Paper at Annual Meeting of Architectural Institute of Japan, B-II, 537-538.

8. Choi B and Tung CCD (2002). "Estimating Sliding Displacement of an Unanchored Body Subjected to Earthquake Excitation”. Earthquake Spectra, 18(4): 601613.

9. Hutchinson TC and Chaudhuri SR (2006). "Simplified Expression for Seismic Fragility Estimation of SlidingDominated Equipment and Contents". Earthquake Spectra, 22(3): 709-732.

10. English R, MacRae GA and Dhakal RP (2012). "Hysteretic influence on earthquake induced sliding damage of contents". 2012 NZSEE Annual Conference, Christchurch, NZ.

11. Konstantinidis DA and Nikfar F (2014). "Seismic response of sliding equipment and contents in base-isolated buildings subjected to broadband ground motions". Earthquake Engineering and Structural Dynamics: 10.1002/eqe.2490.

12. Lin SL, MacRae GA, Dhakal RP and Yeow TZ (2015). "Building contents sliding demands in elastically responding structures". Engineering Structures, 86: 182191.

13. Lin SL, MacRae GA, Dhakal RP, Yeow TZ and English R (2012). "Contents Sliding Response Spectra". 2012 NZSEE Annual Conference, Christchurch, NZ.

14. Meyer E, Overney RM, Dransfeld K and Gyalog T (1998). "Nanoscience - Friction and Rheology on the Nanometer Scale". World Scientific Publishing, Singapore.

15. Shenton III HW and Jones NP (1992). "Base Excitation of Rigid Bodies. Part I: Formulation”. Journal of Engineering Mechanics, 117(10): 2286-2306.

16. Aslam M, Godden WG and Scalise DT (1975). "Sliding Response of Rigid Bodies to Earthquake Motions". Technical Report: University of California, Berkeley, USA.
17. Bureau L, Baumberger T and Caroli C (2002). "Rheological aging and rejuvenation in solid friction contacts". The European Physical Journal E, 8(3): 331-337.

18. Persson BNJ, Albohr O, Mancosu F, Peveri V, Samoilov VN and Sivebaek IM (2003). "On the nature of the static friction, kinetic friction, and creep". Wear, 254(7-8): 835851.

19. Chaudhuri SR and Hutchinson TC (2005). "Characterizing Frictional Behaviour for use in Predicting the Seismic Response of Unattached Equipment". Soil Dynamics and Earthquake Engineering, 25: 591-604.

20. Bar-Sinai Y, Spatschek R, Brener EA and Bouchbinder E (2013). "On the velocity-strengthening behaviour of dry friction". Journal of Geophysical Research: Solid Earth, 119. doi: $10.1002 / 2013 J B 010586$

21. Konstantinidis DA (2008). "Experimental and Analytical Studies on the Seismic Response of Freestanding and Anchored Building Contents". Civil and Environmental Engineering, University of California, Berkeley.

22. Chong WH and Soong TT (2000). "Sliding Fragility of Unrestrained Equipment in Critical Facilities". Technical Report MCEER-00-0005: Department of Civil, Structural and Environmental Engineering, University at Baffalo, New York, USA.

23. Garcia DL and Soong TT (2003). "Sliding Fragility of Block-Type Non-Structural Components. Part 1: Unrestrained Components". Earthquake Engineering and Structural Dynamics, 32: 111-129.

24. Chaudhuri SR and Hutchinson TC (2006). "Fragility of Bench-Mounted Equipment Considering Uncertain Parameters". Journal of Structural Engineering, 132(6): 884-898.

25. Cosenza E, Di Sarno L, Maddaloni G, Magliulo G, Petrone C and Prota A (2015). "Shake table tests for the seismic fragility evaluation of hospital rooms". Earthquake Engineering and Structural Dynamics, 44(1): 23-40.

26. Hedrick TL (2008). "Software techniques for two- and three-dimensional kinematic measurements of biological and biomimetic systems". Bioinspiration \& Biomimetics, 3(3).

27. Newmark NM (1959). "A Method of Computation for Structural Dynamics". Journal of Engineering Mechanics, 85(EM3): 67-94.

28. Field EH, Jordan TH and Cornell CA (2003). "OpenSHA: A Developing Community-Modeling Environment for Seismic Hazard Analysis". Seismological Research Letters, 74(4): 406-419.

29. Stirling MW, McVerry GH, Gerstenberger MC, Litchfield NJ, Van Dissen RJ, Berryman KR, . . and Jacobs K (2012). "National seismic hazard model for New Zealand: 2010 update". Bulletin of the Seismological Society of America, 102(4): 1514-1542. doi: 10.1785/0120110170.

30. Bradley BA (2010a). "NZ-Specific Pseudo-Spectral Acceleration Ground Motion Prediction Equations based on Foreign Models". Department of Civil and Natural Resources Engineering, University of Canterbury, Christchurch, NZ.

31. Bradley BA (2010b). "A Generalized Conditional Intensity Measure Approach and Holistic Ground Motion Selection". Earthquake Engineering and Structural Dynamics, 39(12): 1324-1342. doi: 10.1002/eqe.995.

32. Bradley BA (2012). "A Ground Motion Selection Algorithm Based on the Generalized Conditional Intensity Measure Approach". Soil Dynamics and Earthquake Engineering, 40: 48-61 doi: 10.1016/j.soildyn.2012.04.007. 